\title{
5-year follow-up of a patient with an impacted maxillary canine transplantation and a single-tooth implant: A case report
}

\author{
Hümeyra Kocaelli ${ }^{1}$, Bilge Gökçen Röhlig ${ }^{2}$, Sirmahan Cakarer ${ }^{1},{\text { Mehmet } \text { Yaltirik }^{*}}^{*}$ \\ ${ }^{1}$ Department of Oral Surgery, School of Dentistry, University of Istanbul, Istanbul, Turkey \\ ${ }^{2}$ Department of Prosthodonti, School of Dentistry, University of Istanbul, Istanbul, Turkey \\ Email: "myaltrk@yahoo.com
}

Received 10 January 2012; revised 17 February 2012; accepted 24 February 2012

\begin{abstract}
Background: Despite scientific and technological developments on dentistry, man is still losing their teeth due to several reasons. Tooth loss may result in esthetical and functional discrepancies. Although beginning of dental transplantation is quite old, it started to take attraction on scientific basis recently. In recent years, oral implants are being used nearly in all fields of dentistry. Purpose: The purpose of this study was to evaluate 5 year follow-up of a patient with an impacted maxillary canine transplantation and a single-tooth implant. Materials and Methods: In our study an impacted canine was removed and transplanted immediately. Thereafter the missing premolar was replaced by an implant retained cemented crown. The patient was evaluated clinically and radiographically. Clinical periodontal parameters and implant mobility was evaluated, marginal bone level was measured on radiographs. Results: No significant changes have been observed in these parameters and implant mobility between year one and year five of the study. Conclusion: This study has demonstrated that stable long-term results can be achieved with replacement of single teeth with MIS Implant, and cemented crown on abutment with adjacent transplanted canine, with cumulative success rate for five years.
\end{abstract}

Keywords: Autotransplant; Implant; Impacted

\section{INTRODUCTION}

The constant effort and wish to replace a missing part of a human body has greatly devoted the scientists' time throughout the ages. In ancient times, naive artificial units such as a stone, or wooden implant or even an ani-

*Corresponding author. mal tooth have been used as an anchorage device in jaws $[1,2]$. It was first at the beginning of $18^{\text {th }}$ century that a golden implant in root-form has been used [3]. Thereafter, root formed implants made of different materials; such as silver, platen, gutta-percha, gummy or porcelain has been reported $[4,5]$.

The idea of replacing a missing root with an artificial unit within a biological system without pathological signs and symptoms, to provide support for prosthesis has been developed and the fundamentals of implant dentistry was constructed. Osseointegrated implants were first introduced in mid 1960s. The original concept "ad modum" was based on the placement of four to six standard $3.75 \mathrm{~mm}$ titanium implants in the edentulous mandible anterior to the mental foramina [6]. In a short time dental implantology has showed a great development. They have broadened their indications and become a reliable and widely accepted treatment modality in all fields of dentistry: in the treatment of partial and complete edentulism, in craniofacial surgery, and in orthodontics as an anchorage device, and finally under controlled circumstances in specific areas of pediatric dentistry [7-12].

Recent advances in the field of dental implantology have showed a dramatic increase in the application of osseointegrated implants for replacing single teeth [13]. Even though single tooth implants were not preferred initially because of their technical complexities and esthetic problems [14-16], they are now accepted as standard implant indication $[17,18]$. They have been reported to have a predictable success rate and satisfactory esthetic results similar to that of multi-implant supported restorations [19].

Replacing a missing teeth in the upper anterior region with implants are often preferred to conventional tooth supported restorations, such as bridges or adhesiv restorations or orthodontic space closure, due to their benefit of avoiding the preparation of intact adjacent tooth sub- 
stance and relatively short treatment time.

However there is another treatment alternative; autotransplantation, which is being overlooked in recent years. Autotransplanted teeth have satisfactory functional and aesthetical results under optimal conditions. A de tailed comparison of osseointegrated implants and autotransplantation of teeth is given by Tsukiboshi [20]. The author concluded that the use of natural teeth should always be preferred as long as possible.

The aim of this article is to present a case report of an impacted maxillary canine transplantation and a single tooth implant: a five year follow-up.

\section{CASE}

A 35-year-old man was referred to the University of Istanbul, School of Dentistry, Department of Oral Surgery because of a retained deciduous canine on the left side of the maxilla, causing esthetic problems (Figure 1). The patient rejected an orthodontic treatment because of long treatment time. Impacted canine was relatively high in the alveolar process and was rotated. His left maxillary first premolar tooth was extracted 4 years ago due to the failure of endodontic treatment.

In the clinical examination, the available vertical and mediolateral bone dimensions were determined by orthopantogram and by a diagnostic wax-up. The position of the retained canine in the alveolar process in buccopalatal and in transversal directions, its angulation, its relation to neighboring teeth and its root anatomy were all analyzed. The extraction of the persisted decidous teeth at the recipient site and an immediate transplantation of the retained canine were planned.

The patient's medical history revealed a perfectly healthy adolescent; no medication, no systemic disease, no diabetes or no corticosteroid usage. The surgical procedure was performed under local anesthesia and transplantation technique was presented elsewhere [20]. The canine was finally moved into the exact desired position with respect to occlusion. A radiograph was then made (Figure 2). The sutures were removed one week later. The follow-up examinations were performed every two weeks for three months after the surgery. The root canal treatment of the transplanted teeth was performed ten weeks postoperatively (Figure 3). The fixation was left in place for 12 weeks. No marked root or alveolar bone resorption were observed.

The next step of the treatment was the restoration of the missing first premolar. The patient did not prefer to sacrifice of intact tooth substance of his adjacent teeth, so a single implant placement was planned. A MIS $^{\mathrm{TM}}$ implant $(3.75 \times 10 \mathrm{~mm})$ was placed using a standard two-stage osseointegration procedure.

Four months later the second stage surgery was per- formed and gingival former was placed (Figure 4). Fifteen days later, healing abutment was removed and implant was fitted with the abutment. Metal ceramic crown was fabricated and cemented to the abutment using glass ionemer cement. The porcelain restoration fulfilled the

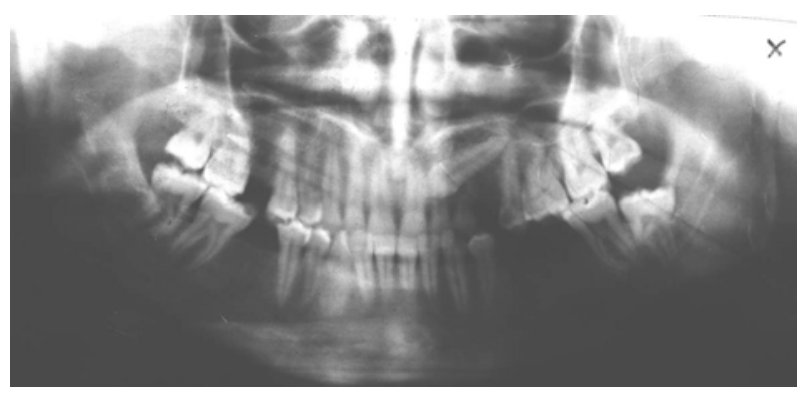

Figure 1. Panoramic radiograph of the impacted canine and retained deciduous canine.

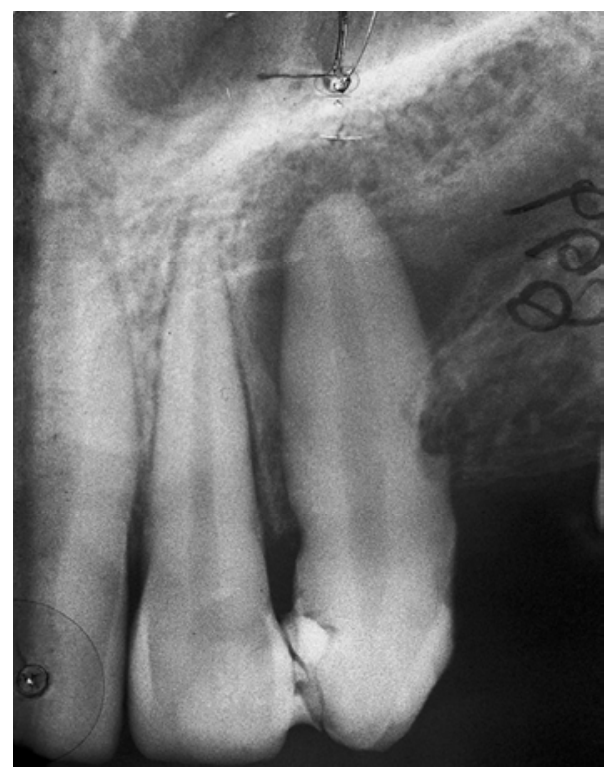

Figure 2. Radiographic picture of the transplanted teeth 3-month follow-up. The root canal treatment of the transplanted teeth was performed. No signs of root resorption is observed.

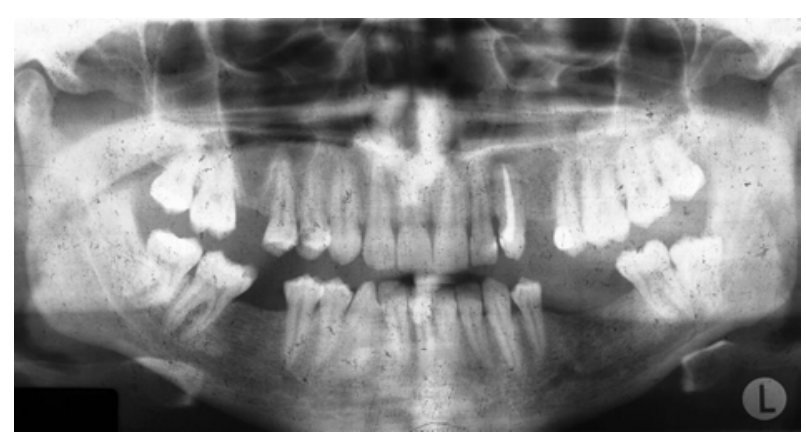

Figure 3. Panaromic radiograph was taken after the single-tooth implant and gingival former was placed. 
esthetical requirements (Figure 5). The patient was recalled 1 week, 6 months and 12 months, one year and five years after the final restoration was placed (Figure 6). At each recall appointments, the implant was assessed using the criteria of success for implants described by Smith and Zarb [21].

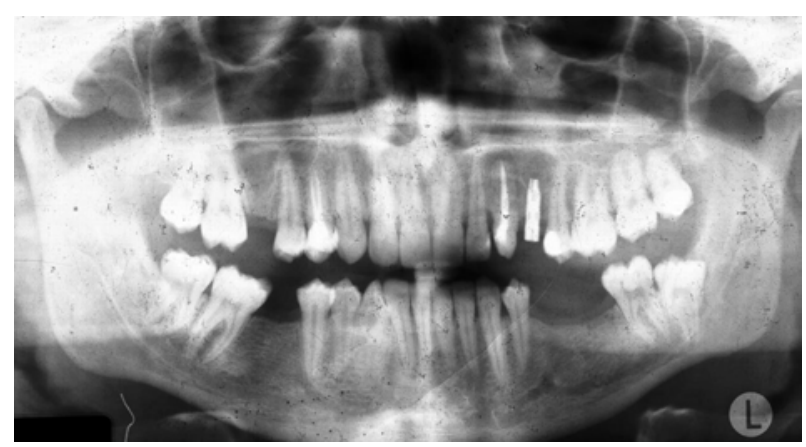

Figure 4. A metal ceramic crown was fabricated and fitted to the abutment.

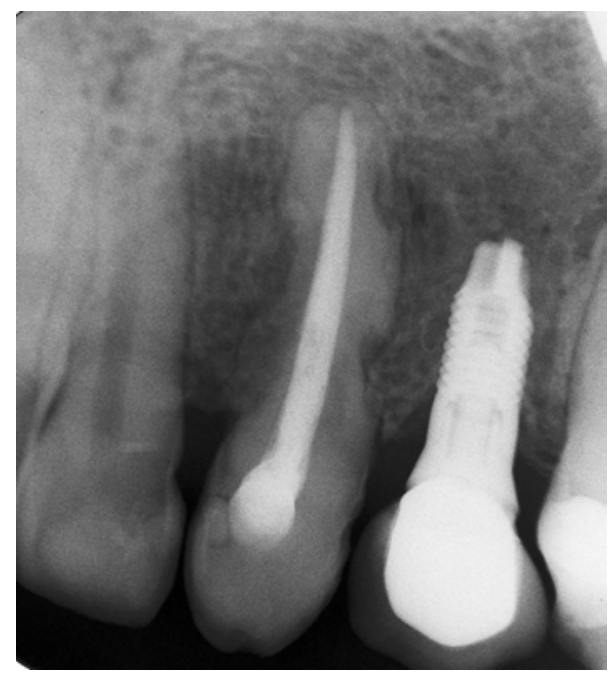

Figure 5. Intraoral view of the final restoration. It has satisfactory aesthetics and full occlusal contact.

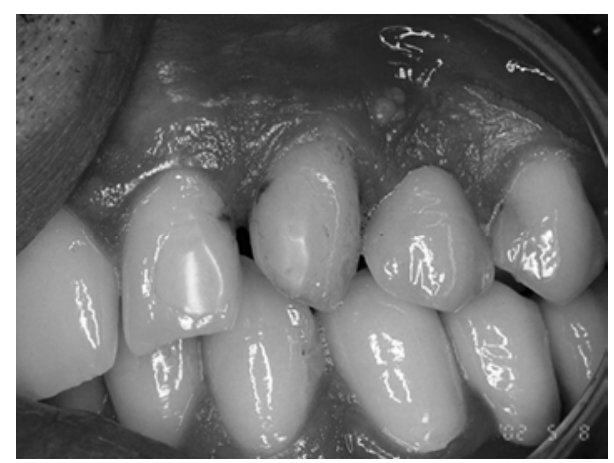

Figure 6. Five year follow-up of the implant. No markable bone resorption was observed around the implant.

\section{DISCUSSION}

This case reported the restoration of a missing maxillary first premolar with a single implant neighboring an impacted maxillary canine transplantation.

Single tooth implants are becoming more increasingly used and today they can be included among the standard implant indications [22]. Regular communications between oral surgeons and orthodontists have become a routine in our clinic regarding the treatment planning for impacted canine. These discussions have led to a reciprocal exchange of knowledge and resulted in modifications to the treatment planning [23].

In the anterior region, there are very obvious esthetic implications when a tooth is absent. The restoration of the anterior region is a challenging procedure. It is often difficult to get satisfactory esthetical results. However for the missing molar and premolar, esthetics may not be the major concern. The single-implants can be a problem free treatment option gratifying results for both the patient and dentist [24]. The ultimate goal of dentistry is the preservation of the teeth and the surrounding structures. However, this goal is not always met by using traditional dental treatment methods. Instead, technical procedures related to tooth replacement sometimes contributes to biological risks that diminish the prognosis of abutment teeth. The use of implants to support dental prostheses demonstrated a tooth preserving effect by avoiding the use of intact teeth during the initial replacement of prostheses, and prevented incorporation of additional abutment teeth [25,26].

Many practitioners are cautious, confused and concerned as to what is in the best interest of the patients. Osteointegrated dental implants are increasingly used to replace a missing teeth in a variety of situations ranging from the missing single tooth to complete edentulous [12,27-29]. Transalveolar transplantation offers the clinician greater flexibility in the treatment of impacted upper canine. Prosthodontic treatment can often be avoided with consequent aesthetic and economic gains [23].

In spite of careful examination and treatment planning in juveniles, impacted canines are likely to continue as a frequent indication of treatment. Good prognosis is achieved when surgeons and orthodontists are in collaboration with meticulous surgical technique and a properly functioning orthodontic appliance is used for the treatment. Achieving predictable aesthetics for single-tooth replacement with implants has not been easy [23,30,31].

In this study, endodontic treatment has been performed later than recommended. The routine has gradually evolved into performing the endodontic treatment two months postoperatively when the stabilization appliance is removed [23]. The advent of concept of os- 
teointegration resulted in dental implant as a predictable clinical reality for long-term use in selected cases [12,17,28,30,32]. Implants can be effective in preserving intact teeth in patients undergoing initial Prosthodontic therapy and preventing the use of additional teeth as abutments in patients whose existing prostheses must be replaced [12,27,33].

In recent years, there has been an increasing need for more data on the use of dental implants in young individuals, regarding whether they should be used at all and, if so, how and when [32,33]. Single implants are alternative to prosthetic replacement, provided that a careful analysis is performed of the individual cases before the implant placement to achieve the best long-term result from an esthetic point of view, and with the least possible distress and suffering for the patient $[12,28]$. The results of Hass et al. suggested that the favorable clinical and esthetic results found in the study encourage an increased application of implants for single tooth restorations. Despite the submucosal edge of the crown, periimplant mucositis was not a major problem. [34] Another study from Lanye et al. indicated that, after one year of function, $97.2 \%$ of implants survived in 88 patients; between the 1- and 3-year follow-up, 100\% survived in 82 patients, giving a 3-year cumulative success rate of $97.2 \%$. No changes were observed in the status of periodontal pocket depth, bleeding index, gingivitis, and tooth-implant mobility from those reported after one year [18].

Single tooth implant replacement is a procedure for the single missing tooth beside the conventional bridgework restorations. It excludes the need to prepare the adjacent tooth, and provides a new treatment option to both dentist and patient. Thus, implant application is a suitable indication for single tooth replacement $[17,26$, 29,31]. The use of implants to prosthetically restore function and aesthetics following the loss of a single tooth become a common treatment alternative to conventional tooth-supported reconstructions, mainly be cause of the benefit of avoiding sacrifice of intact tooth substance of adjacent teeth. Anterior teeth, particularly maxillary teeth, may be lost due to trauma, or may be congenitally absent. As the adjacent teeth are often sound or only minimally restored, there is no indication for crown and bridge treatments $[12,27,28]$. The corresponding value for single-tooth implants was 97.5 percent. When these considerations are combined, the conclusion is that the single-tooth implant is the standard care for the uncomplicated replacement of single missing teeth $[12,33]$.

Replacement of a missing tooth in this "aesthetic zone" is often very sensitive for the patient, and the need for the preparation of the adjacent teeth has made conventional crown a bridge treatment less attractive than an implant-supported crown $[12,27,28]$. The main purpose of the single tooth implant replacement is to protect the adjacent teeth and provide better aesthetic. Its main disadvantages are damage to periodontal tissues, adjacent anatomical landmarks and toot roots with uncareful procedures [22].

Clinical experiences, patient preference, and an evidence-based approach have been combined to build a strong case for single-tooth implant as the undisputed first choice for uncomplicated restorations of the single missing teeth in many situations [34-37]. The singleimplants can be a problem-free treatment option gratifying the results for both the patient and the dentist [24].

\section{CONCLUSION}

It is concluded that an important factor in achieving successful treatment results is the placement of the implant in the correct location, and a detailed treatment planning in single-tooth replacement is essential. Our case demonstrates an immediate transplantation of an impacted canine tooth next to an osseointegrated implant. The aim of our presentation is to evaluate successful single tooth restoration with an implant system and tooth transplantation, and to determine the result of such indication. This study has demonstrated that stable long-term results can be achieved with replacement of single teeth with MIS Implant, and cemented crown on abutment with adjacent transplanted canine, with cumulative success rate for five years.

\section{REFERENCES}

[1] Ring, M.E. (1995) A thousand years of dental implants: A definitive history-Part 1. Compendium of Continuing Education in Dentistry, 16, 1060-1069.

[2] Ring, M.E. (1995) A thousand years of dental implants: A definitive history-Part 2. Compendium of Continuing Education in Dentistry, 16, 1132-1136.

[3] Watzek, G. and Blahout R. (1993) Historischer Rückblick. In: Watzek, G., Ed., Enossale Implantate in der Oralen Chirurgie, Quintessence, Berlin, 17-27.

[4] Berry, A. (1988) Lead roots of teeth for implantation. Journal of Dental Sciences, 8, 549-553.

[5] Andrews, R. (1993) Prehistoric crania from central America. International Dental Journal, 3, 914-915.

[6] Brånemark, P.-I., Adell, R., Breine, U., Hansson, B.O., Lindstrom, J. and Ohlsson, A. (1969) Intra-osseous anchorage of dental prostheses. Experimental studies. Scandinavian Journal of Plastic and Reconstructive Surgery, 3, 81-100. doi:10.3109/02844316909036699

[7] Belser, U.C., Schmid, B., Higginbottom, F., et al. (2004) Outcome analysis of implant restorations located in the anterior maxilla: A review of the recent literature. International Journal of Oral and Maxillofacial Implants, 19, 30- 42.

[8] Naert, I., Koutsikakis, G., Duyck, J., et al. (2002) Biologic outcome of implant-supported restorations in the treatment 
of partial edentulism. Part 1: A longitudinal clinical evaluation. Clinical Oral Implants Research, 13, 381-389. doi:10.1034/j.1600-0501.2002.130406.X

[9] Attart, N.J. and Zarb, G.A. (2004) Long-term treatment outcomes in edentulous patients with implant overdentures: The Toronto study. International Journal of Pro-shodontics, 17, 425-433.

[10] Toljanic, J.A., Eckert, S.E., Roumanas, E., et al. (2005) Osseointegrated craniofacial implants in the rehabilitation of orbital defects: An update of a retrospective experience in the United States. Journal of Prosthetic Dentistry, 94, 177182.

[11] Shapiro, P.A. and Kokich, V.G. (1988) Uses of implants in orthodontics. Dental Clinics of North America, 32, 539-550.

[12] Henry, P. (2000) Tooth loss and implant replacement. Australian Dental Journal, 45, 150-172. doi:10.1111/j.1834-7819.2000.tb00552.x

[13] Cordioli, G., Castagna, S. and Consolati, E. (1994) Single-tooth implant rehabilitation: A retrospective study of 67 implants. International Journal of Prosthodontics, 7, 525-531.

[14] Lill, W., Thornton, B., Reichstaler, J., et al. (1993) Statistical analyses on the success potential of osseointegrated implants: A retrospective single-dimension statistical analysis. Journal of Prosthetic Dentistry, 69, 176-185. doi:10.1016/0022-3913(93)90138-E

[15] Van Steenberge, D., Lekholm, U., Bolender, C., et al. (1990) Applicability of osseointegrated oral implants in the rehabilitation of partial edentulism: A prospective multicenter study on 558 fixtures. International Journal of Oral and Maxillofacial Implants, 5, 272-281.

[16] Lewis, S.G., Beumer, J., Perri, G.R., et al. (1988) Single tooth implant supported restorations. International Journal of Oral and Maxillofacial Implants, 3, 25-30.

[17] Henry, P.J., Laney, W.R., Jemt, T., et al. (1996) Osseointegrated implants for single-tooth replacement: A prospective 5-year multicenter study. International Journal of Oral and Maxillofacial Implants, 11, 450-455.

[18] Laney, W.R., Jemt, T., Harris, D., et al. (1994) Osseointegrated implants for single-tooth replacement: Progressive report from a multicenter prospective study after 3 years. International Journal of Oral and Maxillofacial Implants, 9, 49-54.

[19] Dhanrajani, P.J. and Al-Rafee, M.A. (2005) Single-tooth implant restorations: A retrospective study. Implant Dentistry, 14, 125-130.

[20] Tsukiboshi, M. (2002) Autotransplantation of teeth: Requirements for predictable success. Dental Traumatology, 18, 157-180. doi:10.1034/j.1600-9657.2002.00118.x

[21] Smith, D.E. and Zarb, G.A. (1989) Criteria for success of osseointegrated endosseous implants. Journal of Prothetic Dentistry, 62, 567-72. doi:10.1016/0022-3913(89)90081-4

[22] Scheller, H., Urgel, J.P., Kultje, C., et al. (1998) A 5-year multicenter study on implant-supported single crown restorations. International Journal of Oral and Maxillofacial Implants, 13, 212-218.

[23] Sagne, S., Lennartsson, B. and Thilander, B. (1986) Trans- alveolar transplantation of maxillary canines. An alternative to orthodontic treatment in adult patients. American Journal of Orthodontics and Dentofacial Orthopedics, 90, 149-157. doi:10.1016/0889-5406(86)90047-8

[24] Schmitt, A. and Zarb, G.A. (1993) The longitudinal clinical effectiveness of osseointegrated dental implants for single-tooth replacement. International Journal of Prosthodontics, 6, 197-202.

[25] Priest, G. (1999) Single-tooth implant and their role in preserving remaining teeth: A 10-year survival study. International Journal of Oral and Maxillofacial Implants, 14, 181-188.

[26] Henry, P.J. (1999) Clinical experiences with dental implants. Advances in Dental Research, 13, 147-152. doi:10.1177/08959374990130010401

[27] Albrektsson, T. (1988) A multicenter report on osseointegrated oral implants. Journal of Prosthetic Dentistry, 60, 75-84. doi:10.1016/0022-3913(88)90355-1

[28] Qunne, J., Astrand, P., Ahlen, K., et al. (1992) Implants in partially edentulous patients: A longitudinal study of bridges supported by both implants and natural teeth. Clinical Oral Implants Research, 3, 49-56. doi:10.1034/j.1600-0501.1992.030201.x

[29] Thilander, B., Ödman, J. and Jemt, T. (1999) Single implants in the upper incisor region and relationship to the adjacent teeth: An 8-year follow-up study. Clinical Oral Implants Research, 10, 346-355. doi:10.1034/j.1600-0501.1999.100502.x

[30] Chang, M., Wennström, L., Ödman, P., et al. (1999) Implant supported single-tooth replacements compared to contralateral natural teeth: Crown and soft tissue dimensions. Clinical Oral Implants Research, 10, 185-194. doi:10.1034/j.1600-0501.1999.100301.x

[31] Moberg, L.A., Köndell, P.A., Kulman, L., et al. (1999) Evaluation of single-tooth restorations on ITI dental implants: A prospective study of 29 patients. Clinical Oral Implants Research, 10, 45-53. doi:10.1034/j.1600-0501.1999.100106.x

[32] Dao, T.T.T., Anderson, J.D. and Zarb, G.A. (1993) Is osteoporosis a risk factor for osseointegration of dental implants? International Journal of Oral and Maxillofacial Implants, 8, 137-144.

[33] Chapman, R.J. (1995) Single tooth implant aesthetics. Dentistry Today, 14, 3-5.

[34] Hass, R., Mensdorff-Pouilly, N., Mailath, M.D., et al. (1995) Brånemark single-tooth implants: A preliminary report of 76 implants. Journal of Prosthetic Dentistry, 73, 274-279. doi:10.1016/S0022-3913(05)80205-7

[35] Abu Tair, J.A. and Rahhal, A. (2010) Tooth autotransplantation in orthodontic patients. Journal of Contemporary Dental Practice, 11, 63-70.

[36] Newman, M.G. (1999) The single tooth implants as a standard of care. International Journal of Oral and Maxillofacial Implants, 14, 621-622.

[37] Taltı, U., Kürkçü, M., Cam, O.Y. and Büyükyılmaz T. (2009) Autotransplantation of impacted teeth: A report of 3 cases and review of literature. Quintessence International, $\mathbf{4 0}$ 589-595. 